\title{
A Comparison of Health-Related Quality of Life among Normal-Weight, Overweight and Obese Adults in Qazvin Metabolic Diseases Study (QMDS), Iran
}

\author{
Health-Related Quality of Life among Obese Adults
}

\begin{abstract}
Azam Ghorbani ${ }^{1}$, Amir Ziaee ${ }^{2}$, Ahmad Afaghi $^{2} \&$ Sonia Oveisi ${ }^{2}$
${ }^{1}$ Instructor of Nursing, Faculty of Nursing, Metabolic Diseases Research Center, Qazvin University of Medical Sciences, Qazvin, Iran

${ }^{2}$ Metabolic Diseases Research Center, Qazvin University of Medical Sciences, Qazvin, Iran

Correspondence: Amir Ziaee, Associate Professor of Endocrinology, Metabolic Diseases Research Center, Booali-Sina Hospital, Booali-Sina Street, Qazvin, Iran. Tel: 98-281-336-0084. Fax: 98-281-332-6033. E-mail: aziaee1963@yahoo.com
\end{abstract}

Received: January 19, 2012 Accepted: January 31, 2013 Online Published: February 26, 2013

doi:10.5539/gjhs.v5n3p156 URL: http://dx.doi.org/10.5539/gjhs.v5n3p156

Conflict of interest: nothing to declare

This study was supported by a grant from the research department of Qazvin University of Medical Sciences

\begin{abstract}
Background: Obesity is a public health problem that has raised concern worldwide. Numerous epidemiological studies have been showed the relationship between obesity, abdominal fatness and risk of a wide range of illnesses (i.e. diabetes). Obese people experience health-related quality-of-life (HRQL) impairments. The purpose of this study was to evaluate the effect of BMI on Quality of Life, among Normal-Weight, Overweight and Obese adults in Qazvin, Iran. Methods: This Cross-Sectional study was conducted on 1103 subjects (aged 20-78 years old) from September 2010 to April 2011 in Qazvin, Iran. The study subjects were selected by multistage cluster random sampling method from residents of mindoodar district of Qazvin. Obesity was defined based on Body Mass Index and SF-36 questionnaire was used as measurement instrument for quality of life. Data were analyzed by Chi-square test, ANOVA and MANOVA. Results: A total of 527 men and 576 women were entered the study. Mean BMI was $25.97 \pm 4.5 \mathrm{Kg} / \mathrm{m}^{2}$. The scores of 6 domains were significantly different between 3 groups of BMI. The differences of physical component summary (PCS) and mental component summary (MCS) scores were also significant between normal weight, overweight and obese subjects ( $<<0.001$ and $p<0.025$, respectively). Conclusion: This study underlines the importance of HRQL in overweight and obese individuals. These results suggest that more attention to the obesity and overweight is needed in Iranian population.
\end{abstract}

Keywords: health-related quality of life, obesity, overweight, BODY MASS INDEX, physical functioning

\section{Introduction}

With increasing obesity as major health related problem around the world, variety of chronic diseases such as coronary artery disease, hypertension, type II diabetes, and several cancers have become the second leading avoidable cause of mortality in Western countries (Chan \& Woo, 2010; Guh et al., 2009; Pi-Sunyer, 2009). Apart from that emerging issue of association between obesity and Health-Related quality of life (HRQL) has gained increasing interest as an outcome measure in clinical setting, public health and among researchers. The phenomenon of quality of life (QOL) is subjective and is reported according to a person's own experiences and is a combination of physical, psychological, social, emotional, public stress, self-esteem, sexual and work functional domains (Kolotkin \& Crosby, 2002a; de Zwaan et al., 2009; Tsai, Yang, Lin, \& Fang, 2004). Even, some psychosomatic researchers have focused on pain and mental health issues in HRQL area (Fontaine \& Barofsky, 2001; Kolotkin, Crosby, \& Williams, 2002b; Saraç et al., 2007). Investigations on the relationship between HRQL and body mass index (BMI) demonstrated that HRQL impairment worsens with increasing obesity (Kolotkin \& 
Crosby, 2002a; Kolotkin et al., 2002b; Fontaine \& Bartlett, 1998). The negative effects of obesity on the dimensions of HRQL have been discussed in some reports (Kolotkin \& Crosby, 2002a; Kolotkin et al., 2002b; Imai et al., 2008). More over several studies have demonstrated the negative relationship between severity of obesity and well-being and also among obese subjects without chronic disease the physical well-being suppress (Doll, Petersen, \& Stewart-Brown, 2000). However in some studies the stronger correlation between obesity and HRQL has been observed among women than men (AHRQ Research Activities, 2007), in others, the domains of HRQL have been influenced by education level (García-Mendizábal et al., 2009).

The HRQL among normal-weight, overweight and obese adults has been investigated in some studies. The results showed that the normal weight individuals had better performance in the physical functioning domain compared to other two groups. Overweight individuals had also better performance than the obese group in this domain (de Zwaan et al., 2009; Tsai et al., 2004; Sirtori et al., 2011; Llaneza et al., 2007; Larsson, Karlsson, \& Sullivan, 2002). As regards obesity has become a nationwide epidemic, and this condition is a risk factor for many chronic disease and although several studies have shown the correlation between obesity and poor level of health-related quality of life (HRQL), this is the first study to correlate BMI on quality of life the adult Iranian population; therefore we aimed to evaluate the effect of BMI on quality of life, among normal-weight, overweight and obese adults in Qazvin, Iran.

\section{Methods}

\subsection{Subjects}

The Cross-Sectional study was conducted on 1103 subjects (aged 20-78 years old) from September 2010 to April 2011 in Qazvin (this city is located $150 \mathrm{~km}$ northwest of Tehran), Iran. The research project was approved by medical research ethics committee of Qazvin University of Medical Sciences.

The study subjects were selected by multistage cluster random sampling methods from residents of mindoodar district of Qazvin, All households of the district had health profiles at minoodar health center and the sampling unit was the household. The district was divided in to four main cluster according to the population size .Subjects were invited by phone call to attend the study at the health center and after face to face explanation of the study details, they were free to participate. Details of sampling have been reported elsewhere (Ziaee, Esmailzadehha, Ghorbani, \& Asefzadeh, 2013). All subjects gave their written informed consent. Inclusion criteria were age $\geq 20$ years and no underlying disease. Exclusion criteria included pregnancy, dealing with a mental crisis (such as a family member's death, mental and physical illness, etc) according to the subjects' report at the time of study.

\subsection{Data Collection}

Demographic and social data were self-reported in the questionnaire given to the subjects. Two general practitioners filled out the organized questionnaire were prepared from a literature review and face and contact validity of this tool were approved by five experts. Height and weight were measured. Body mass index (BMI) was calculated as weight $(\mathrm{kg})$ divided by the height $(\mathrm{m})$ squared. Normal weight was defined as $\mathrm{BMI}<25$, overweight was defined as $25 \leq \mathrm{BMI}<30$ and obesity was defined as BMI $\geq 30$. To assess subjects' HRQL, the authors used the short Form of Health Survey (SF-36) questionnaire which has been translated and adapted for Iranian population with the Cranach's alpha coefficients ranging from 0.77 to $0.90($ alpha $=0.65)$ and Convergent validity ranging from 0.58 to 0.95 (Montazeri, Goshtasebi, Vahdaninia, \& Gandek, 2005). Data were self-reported in the SF-36 questionnaire given to the subjects. The SF-36 questionnaire (Iranian version) which adapted for Iranian population using a well-known tool for assess health-related quality of life. This questionnaire contains 36 questions which measure eight separate dimensions including physical functioning, role-physical, bodily pain, general health, vitality, social functioning, role emotional and mental health. Two aggregate scores reflect physical component summary (PCS) and mental component summary (MCS). Each domain is scored from 0 to 100 where higher scores correspond to a better health-related QOL.

\subsection{Data Analysis}

Statistical analysis: For description of subjects, all variables were presented as frequency, percentage or mean plus or minus standard deviation (SD). Data were analyzed by Chi-square test and analysis of variance (ANOVA). A general lineal model analysis (MANOVA) was also used to compare the scores of BMI groups on the basis of gender. Multivariate logistic regression analyses were run using dichotomized Z-scores on individual domains of SF-36 as dependent variable. This model was adjusted for BMI. Significance level was set as $\mathrm{P}<0.05$. 


\section{Results}

A total of 527 men and 576 women aged 20-78 years were entered the study. Mean BMI was $25.97 \pm 4.5 \mathrm{Kg} / \mathrm{m}^{2}$. The mean age among normal weight, overweight, and obese subjects were $36.55 \pm 12.39,42.63 \pm 8.39$ and $42.9 \pm 9.06$ years, respectively. 464 subjects $(42.06 \%)$ had normal weight, 451 subjects $(40.9 \%)$ were overweight and 188 subjects $(17.04 \%)$ were obese. $39.7 \%$ of females were overweight and $24.1 \%$ of them were obese. In the male population, $42.1 \%$ were overweight and $9.29 \%$ were obese.

Socio-demographic characteristics of study subjects are shown in Table 1.in relation to the work status ,obese men were more likely to have part (in comparison with normal weight men who had full time job), and the majority of obese women were housewife. The academic education level was higher in normal weight group when compared to overweight and obese groups.

Table 1. Socio-demographic characteristics of study subjects

\begin{tabular}{|c|c|c|c|c|c|}
\hline & \multicolumn{3}{|c|}{ BMI } & \multirow{2}{*}{ Total } & \multirow{2}{*}{ P-Value } \\
\hline & $<\mathbf{2 5}$ & 25-30 & $>\mathbf{3 0}$ & & \\
\hline \multicolumn{6}{|l|}{ Sex } \\
\hline Male & $256(55.2)$ & $222(49.2)$ & $49(26.1)$ & $527(47.8)$ & \multirow[t]{2}{*}{$<0.001$} \\
\hline Female & $208(44.8)$ & $229(50.8)$ & $139(73.9)$ & $576(52.2)$ & \\
\hline \multicolumn{6}{|l|}{ Age } \\
\hline $20-29$ & $155(33.5)$ & $27(6)$ & $12(6.6)$ & 194(17.7) & \multirow{5}{*}{$<0.001$} \\
\hline $30-39$ & $106(22.9)$ & $114(25.3)$ & $47(25.7)$ & $267(24.4)$ & \\
\hline $40-49$ & $154(33.3)$ & $232(51.6)$ & $91(49.7)$ & $477(43.6)$ & \\
\hline $50-59$ & $35(7.6)$ & $62(13.8)$ & $23(12.6)$ & $120(11)$ & \\
\hline $60>$ & $12(2.6)$ & $15(3.3)$ & $10(5.5)$ & $37(3.4)$ & \\
\hline \multicolumn{6}{|l|}{ Education } \\
\hline No Formal Education & $5(1.1)$ & $11(2.4)$ & $17(9.1)$ & $33(3)$ & \multirow{3}{*}{$<0.001$} \\
\hline$<12$ years & $322(69.5)$ & $377(84)$ & $156(83.9)$ & $855(77.9)$ & \\
\hline$>12$ years & $136(29.4)$ & $61(13.6)$ & $13(7)$ & $210(19.1)$ & \\
\hline \multicolumn{6}{|l|}{ Work Status } \\
\hline Employed & $213(46.2)$ & $157(34.9)$ & $32(17.3)$ & $402(36.7)$ & \multirow{4}{*}{$<0.001$} \\
\hline Unemployed & $46(10)$ & $7(1.6)$ & $1(0.5)$ & $54(4.9)$ & \\
\hline Housewife & $132(28.6)$ & $202(44.9)$ & $130(70.3)$ & $464(42.3)$ & \\
\hline Pensioner(Retired) & $70(15.2)$ & $84(18.7)$ & $22(11.9)$ & $176(16.1)$ & \\
\hline
\end{tabular}

Data are shown as Number (percent).

The scores of 6 domains were significantly different between 3 groups of BMI (Table 2). From a total of eight domain studied, six of them were different among the groups based on BMI (physical functioning, role physical, bodily pain, general health, vitality and social functioning). The differences of PCS and MCS scores were also significant between normal weight, overweight and obese subjects $(\mathrm{p}<0.001$ and $\mathrm{p}<0.025$, respectively). Comparing the scores of 8 domain of HRQL of normal weight, overweight, and obese groups showed that among all domains, only the role physical domain showed significant difference between two sexes $(p<0.001)$. Among females the PCS score was significantly different between normal weight, overweight and obese subjects $(\mathrm{p}<0.001)$. General linear model analyses revealed that the BMI and sex had significant effect in role physical domain $(\mathrm{P}<0.001)$. The Z-scores on SF-36 domains, showed the impairment of HRQL in comparison with BMI and reflecting that HRQL was particularly poor in physical component summary (PCS) in obese subjects. SF-36 $Z$-scores in three groups are summarized in Figure 1. 
Table 2. SF-36 scores of health-related quality of life in 3 groups of study population

\begin{tabular}{lcccccc}
\hline \multirow{2}{*}{ Domains } & \multirow{2}{*}{ Total } & \multicolumn{3}{c}{ BMI } & \multirow{2}{*}{ F } & P-value \\
\cline { 3 - 5 } & & $\mathbf{2 5}$ & $\mathbf{2 5 - 3 0}$ & $\mathbf{3 0}$ & & \\
\hline Physical & $79.4 \pm 21.7$ & $83.51 \pm 19.75$ & $74.48 \pm 22.05$ & $72.23 \pm 22.59$ & 19.84 & $<0.001$ \\
Functioning & $69.5 \pm 34.6$ & $74.94 \pm 32.59$ & $67.29 \pm 34.44$ & $62.10 \pm 38.03$ & 11.128 & $<0.001$ \\
Role Physical & $63.8 \pm 21.4$ & $66.76 \pm 20.09$ & $62.79 \pm 21.88$ & $59.14 \pm 22.40$ & 9.53 & $<0.001$ \\
Bodily Pain & $62.2 \pm 17.7$ & $63.65 \pm 17.56$ & $62.31 \pm 18.09$ & $58.54 \pm 16.72$ & 5.61 & 0.004 \\
General Health & $61.4 \pm 18.2$ & $62.78 \pm 18.22$ & $61.70 \pm 18.43$ & $57.5 \pm 17.27$ & 5.73 & 0.003 \\
Vitality & $74.9 \pm 21.4$ & $75.21 \pm 21.35$ & $76.38 \pm 20.53$ & $71.07 \pm 23.31$ & 4.13 & 0.016 \\
Social Functioning & $66.7 \pm 37.6$ & $66.30 \pm 38.78$ & $68.36 \pm 36.023$ & $63.47 \pm 38.09$ & 1.15 & 0.315 \\
Role Emotional & $66.5 \pm 17.9$ & $67.12 \pm 18.34$ & $66.92 \pm 17.81$ & $63.80 \pm 17.34$ & 2.51 & 0.081 \\
Mental Health & $68.77 \pm 18.18$ & $72.22 \pm 16.90$ & $67.72 \pm 18.20$ & $63.0 \pm 19.36$ & 19.17 & $<0.001$ \\
Physical (PCS) & $67.42 \pm 19.16$ & $67.85 \pm 19.53$ & $68.34 \pm 18.55$ & $63.96 \pm 19.44$ & 3.71 & 0.025 \\
Mental(MCS) & & & & & &
\end{tabular}

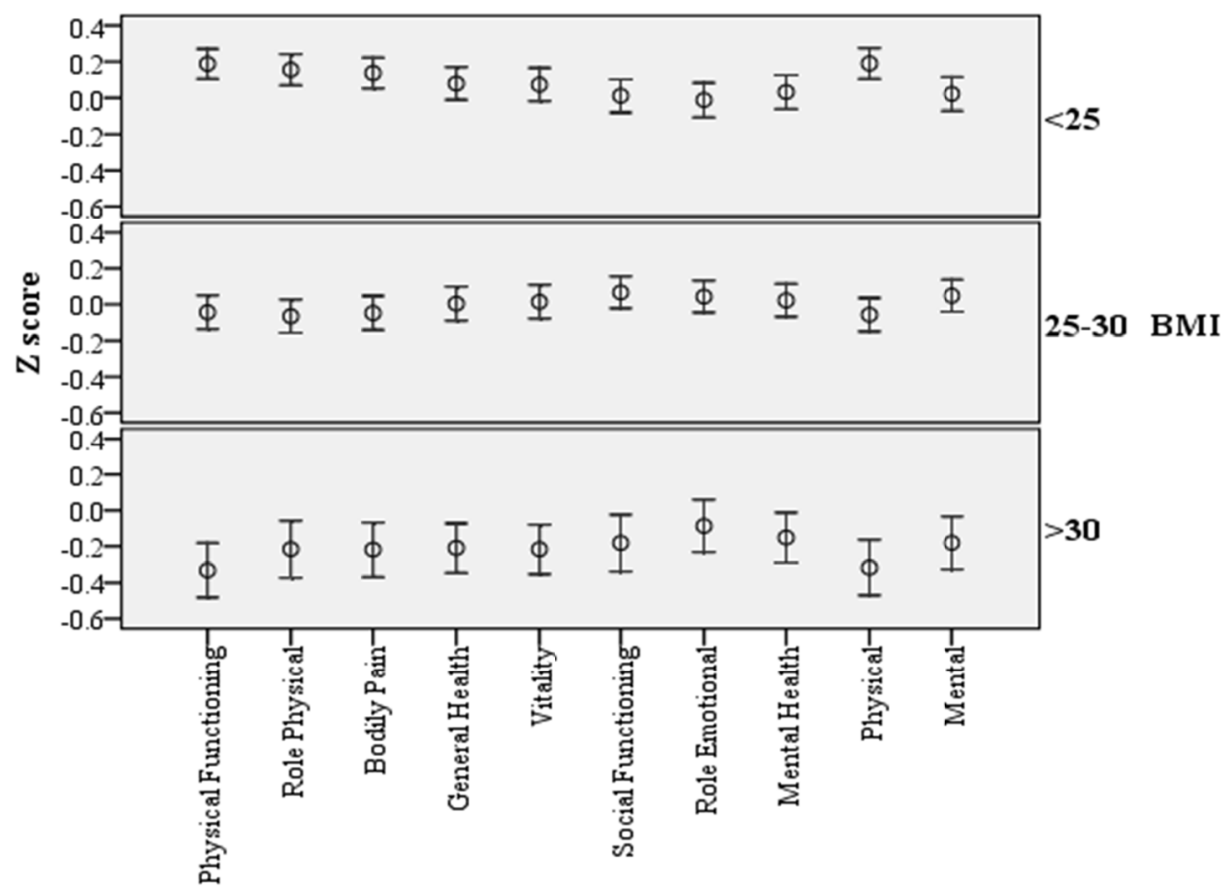

Figure 1. Z-score on short Form-36 in relation to normal weight, overweight and obesity. Data are presented as means and $95 \%$ confidence intervals

\section{Discussion}

Our findings showed that overweight and obese subjects suffered from poor HRQL and had lower scores than normal weight subjects. This study revealed that HRQL of overweight and obese subjects in 6 domains were significantly different from normal weight subjects. These differences were in physical functioning, role physical, bodily pain, general health, vitality and social functioning.

The current findings were similar to previous reports (Tsai et al., 2004; Mannucci et al., 2010; Williams, Wake, Hesketh, Maher, \& Waters, 2005; Vasiljevic et al., 2008; Saraç et al., 2007). Vasilgeic et al. (2008) reported that in Belgrad population the normal weight subjects compared to overweight and obese subjects had significant differences in 7 domains' scores, while in a study conducted in Turkey by Sarac et al. (2007), these differences were reported in 6 domains. 
Considering that overweight and obesity affect physical health and limit the daily activity of subjects (Alley \& Chang, 2007), increasing BMI causes HRQL decrease in physical domains (Larsson et al., 2002; Vasiljevic et al., 2008; Saraç et al., 2007; Alley \& Chang, 2007; Wiczinski, Döring, John, von Lengerke \& KORA Study Group, 2009). Although in our study increasing BMI resulted in suppression of all domains of HRQL scores, this negative effect was more severe in physical domains. Several reports have discussed the relationship between increasing BMI and complaining from physical disorders and incompetency (Ucan \& Ovayolu, 2010; Dinç et al., 2006; Kolotkin, Meter, \& Williams, 2001). Other studies found that, increasing severity of obesity resulted in reducing general health (Richards, Adams, \& Hunt, 2000) and increasing number of physical disorders (de Zwaan et al., 2009; Sirtori et al., 2011). Our findings is similar to previous mentioned studies and the significant differences in scores of bodily pain, role physical, and general health domains between normal weight and obese groups confirm these findings.

Wen-Ling Tsai also confirmed the relationship between increase in BMI and physical functioning, bodily pain, physical role limitations in women (Tsai, 2004). Moreover, in a study conducted in Korean adults by Song, obese women had lower QOL than men (Song et al., 2010). Our results showed close relationship between QOL and physical domains that corresponds with previous reports (de Zwaan et al., 2009; Doll et al., 2000; Fontaine et al., 1998). It seems that the physical QOL domains will progressively impair with increasing BMI and age. We can conclude that overweight and obesity have a major role in the poor HRQL (de Zwaan et al., 2009).

Our results showed significant differences between physical domains and education in women. Obese women with lower education had lower physical QOL, which was similar with the results in Spanish women (García-Mendizábal et al., 2009). On the other hand, researchers emphasized that these differences in women with higher level of education were not significant. We can conclude that obesity and low education could be one of the most important predictor of QOL in both physical and psychosocial domains (de Zwaan et al., 2009).

The present study demonstrated significant relationship between BMI and some mental domains of QOL. Weak relationship between mental domains' scores and BMI in obese and non-obese subjects has been reported in many studies (de Zwaan et al., 2009; Doll et al., 2000; Saraç et al., 2007). Although the impact of overweight and obesity on mental health is controversial (García-Mendizábal et al., 2009); some reports state that obesity cannot be associated with an increase in mental disorders (Friedman \& Brownell, 1995). According to available documents and the importance of women's role in family, special consideration should be placed on future health plans; because the risk of mental health problems are higher in obese subjects than in normal-weight and overweight population. In addition the risk of depression and suicidal thoughts are higher in women (de Zwaan et al., 2009; Saraç et al., 2007; Roberts, Kaplan, Shema, \& Strawbridge, 2000) .

In 2010, the World Health Organization reported about the Changing pattern of diseases towards chronic and non-communicable diseases and prevalence of obesity in the world (World Health Organization Global database on body mass index, 2010). In addition, obesity has a negative impact on health issue of population (especially women of reproductive age) and physical problems such as infertility, a variety of non-communicable diseases, cancer and other conditions (World Health Organization Global database on body mass index, 2010; Chescheir, 2011) and reduces physical and mental QOL. Preparation of health goals, action plans and multi disciplinary approaches (Montazeri et al., 2005) with regard to the social and demographic characteristics of each region are required (Musaiger, 2011).

The strengths of this study are the inclusion of a large sample, the direct measurement of anthropometric indices, this is the first study correlating body mass index (BMI) and quality of life of the adult Iranian population, using a well-known questionary (SF-36), which has translated and adapted for Iranian population. Lack of detailed information about undiagnosed physical problems and social and economic issues of the subjects' life are limitations of the current study.

In summary, assessment of quality of life had been considered in different communities. The study showed that the overweight and obese subjects suffer from poor HRQL, as the increase in BMI had lowered the domains of HRQL. The physical domain was more severe affected by obesity. The authors suggest the use of HRQL as outcome measurement in treatment programs. Based on results, more attention to quality of life in health promotion programs in obese and overweight groups in necessary for physical and social well-being Iranian population.

\section{Acknowledgements}

The authors would like to thank the participants involved in this study and the department of research of Qazvin University of Medical Science for endorsing the project. The authors would also like to thank Mrs Zahra Mohammadi and Miss Mahsa Khoshpanjeh for Their help in preparing this paper. 


\section{References}

Alley, D. E., \& Chang, V. W. (2007). The changing relationship of obesity and disability, 1988-2004. JAMA, 298(17), 2020-7. http://dx.doi.org/10.1001/jama.298.17.2020

Chan, R. S., \& Woo, J. (2010). Prevention of overweight and obesity: how effective is the current public health approach. Int J Environ Res Public Health, 7(3), 765-83. http://dx.doi.org/10.3390/ijerph7030765

Chescheir, N. C. (2011). Global obesity and the effect on women's health. Obstet Gynecol, 117(5), 1213-22. http://dx.doi.org/10.1097/AOG.0b013e3182161732.

de Zwaan, M., Petersen, I., Kaerber, M., Burgmer, R., Nolting, B., Legenbauer, T., ... Herpertz, S. (2009). Obesity and quality of life: a controlled study of normal-weight and obese individuals. Psychosomatics, 50(5), 474-82. http://dx.doi.org/10.1016/S0033-3182(09)70840-0

Dinç, G., Eser, E., Saatli, G. L., Cihan, U. A., Oral, A., Baydur, H., \& Ozcan, C. (2006). The relationship between obesity and health related quality of life of women in a Turkish city with a high prevalence of obesity. Asia Pac J Clin Nutr, 15(4), 508-15.

Doll, H. A., Petersen, S. E., \& Stewart-Brown, S. L. (2000). Obesity and physical and emotional well-being: associations between body mass index, chronic illness, and the physical and mental components of the SF-36 questionnaire. Obes Res, 8(2), 160-70. http://dx.doi.org/10.1038/oby.2000.17

Fontaine, K. R., \& Bartlett, S. J. (1998). Estimating health related quality of life in obese individuals. Dis Manage Health Outcomes, 3, 61-70. http://dx.doi.org/10.2165/00115677-199803020-00002

Fontaine, K. R., \& Barofsky, I. (2001). Obesity and health-related quality of life. Obes Rev, 2(3), 173-82. http://dx.doi.org/10.1046/j.1467-789x.2001.00032.x

Friedman, M. A., \& Brownell, K. D. (1995). Psychological correlates of obesity: moving to the next research generation. Psychol Bull, 117(1), 3-20. http://dx.doi.org/10.1037//0033-2909.117.1.3

García-Mendizábal, M. J., Carrasco, J. M., Pérez-Gómez, B., Aragonés, N., Guallar-Castillón, P., Rodríguez-Artalejo, F., ... Pollán, M. (2009). Role of educational level in the relationship between Body Mass Index (BMI) and health- related quality of life (HRQL) among rural Spanish women. BMC Public Health, 9(120), 1-10. http://dx.doi.org/10.1186/1471-2458-9-120

Guh, D. P., Zhang, W., Bansback, N., Amarsi, Z., Birmingham, C. L., \& Anis, A. H. (2009). The incidence of co-morbidities related to obesity and overweight: a systematic review and meta-analysis. BMC Public Health, 9, 88. http://dx.doi.org/10.1186/1471-2458-9-88

Imai, K., Gregg, E. W., Chen, Y. J., Zhang, P., de Rekeneire, N., \& Williamson, D. F. (2008). The association of BMI with functional status and self-rated health in US adults. Obesity (Silver Spring), 16(2), 402-8. http://dx.doi.org/10.1038/oby.2007.70

Kolotkin, R. L., Meter, K., \& Williams, G. R. (2001). Quality of life and obesity. Obes Rev, 2(4), 219-29. http://dx.doi.org/10.1046/j.1467-789X.2001.00040.x

Kolotkin, R. L., \& Crosby, R. D. (2002). Psychometric evaluation of the impact of weight on quality of life-lite questionnaire (IWQOL-lite) in a community sample. Qual Life Res, 11(2), 157-71.

Kolotkin, R. L., Crosby, R. D., \& Williams, G. R. (2002). Health-related quality of life varies among obese subgroups. Obes Res, 10(8), 748-56. http://dx.doi.org/10.1038/oby.2002.102

Larsson, U., Karlsson, J., \& Sullivan, M. (2002). Impact of overweight and obesity on health-related quality of life Fa Swedish population study. Int J Obes Relat Metab Disord, 26, 417-24.

Llaneza, P., Iñarrea, J., Gonzalez, C., Alonso, A., Arnott, I., \& Ferrer-Barriendos, J. (2007). Differences in health related quality of life in a sample of Spanish menopausal women with and without obesity. Maturitas, 58(4), 387-94. http://dx.doi.org/10.1016/j.maturitas.2007.09.013

Mannucci, E., Petroni, M. L., Villanova, N., Rotella, C. M., Apolone, G., Marchesini, G., \& QUOVADIS Study Group. (2010). Clinical and psychological correlates of health-related quality of life in obese patients. Health Qual Life Outcomes, 8, 90. http://dx.doi.org/10.1186/1477-7525-8-90

Montazeri, A., Goshtasebi, A., Vahdaninia, M., \& Gandek, B. (2005). The Short Form Health Survey (SF-36): translation and validation study of the Iranian version. Qual Life Res, 14(3), 875-82. http://dx.doi.org/10.1007/s11136-004-1014-5 
Musaiger, A. O. (2011). Overweight and obesity in eastern mediterranean region: prevalence and possible causes. J Obes, 2011, 407237. http://dx.doi.org/10.1155/2011/407237

Pi-Sunyer, X. (2009). The medical risks of obesity. Postgrad Med, 121(6), 21-33. http://dx.doi.org/10.3810/pgm.2009.11.2074.

Richards, M. M., Adams, T. D., \& Hunt, S. C. (2000). Functional status and emotional well-being, dietary intake, and physical activity of severely obese subjects. J Am Diet Assoc, 100(1), 67-75.

Roberts, R. E., Kaplan, G. A., Shema, S. J., \& Strawbridge, W. J. (2000). Are the obese at greater risk for depression? Am J Epidemiol, 152(2), 163-70. http://dx.doi.org/10.1093/aje/152.2.163

Saraç, F., Parýldar, S., Duman, E., Saygýlý, F., Tüzün, M., \& Yýlmaz, C. (2007). Quality of life for obese women and men in Turkey. Prev Chronic Dis, 4(3), A50.

Sirtori, A., Brunani, A., Liuzzi, A., Pasqualinotto, L., Villa, V., Leonardi, M., \& Raggi, A. (2011). Quality of life, disability, and body mass index are related in obese patients. Int J Rehabil Res, 34(3), $270-2$. http://dx.doi.org/10.1097/MRR.0b013e328347be15

Song, H. R., Park, H. S., Yun, K. E., Cho, S. H., Choi, E. Y., Lee, S. Y., .. Bae, S. C. (2010). Gender and age differences in the impact of overweight on obesity-related quality of life among Korean adults. Obesity Research \& Clinical Practice, 4, e15- e23. http://dx.doi.org/10.1016/j.orcp.2009.07.003

Tsai, W. L., Yang, C. Y., Lin, S. F., \& Fang, F. M. (2004). Impact of obesity on medical problems and quality of life in Taiwan. Am J Epidemiol, 160(6), 557- 65. http://dx.doi.org/10.1093/aje/kwh251

Ucan, O., \& Ovayolu, N. (2010). Relationship between diabetes mellitus, hypertension and obesity, and health-related quality of life in Gaziantep, a central south-eastern city in Turkey. J Clin Nurs, 19(17-18), 2511-9. http://dx.doi.org/10.1111/j.1365-2702.2010.03295.x

Vasiljevic, N., Ralevic, S., Marinkovic, J., Kocev, N., Maksimovic, M., Milosevic, G. S., \& Tomic, J. (2008). The assessment of health-related quality of life in relation to the body mass index value in the urban population of Belgrade. Health Qual Life Outcomes, 6, 106. http://dx.doi.org/10.1186/1477-7525-6-106

Wiczinski, E., Döring, A., John, J., von Lengerke, T., \& KORA Study Group. (2009). Obesity and health-related quality of life: does social support moderate existing associations? Br J Health Psychol, 14(Pt 4), 717-34. http://dx.doi.org/10.1348/135910708X401867

Williams, J., Wake, M., Hesketh, K., Maher, E., \& Waters, E. (2005). Health-related quality of life of overweight and obese children. JAMA, 293(1), 70-6. http://dx.doi.org/10.1001/jama.293.1.70

AHRQ Research Activities. (2007). Women are more likely than men to suffer health problems and worse quality of life due to obesity. Retrieved from http://archive.ahrq.gov/research/jan07/0107RA19.htm

World Health Organization Global database on body mass index. (2010). Retrieved from http://apps.who.int/bmi/index.jsp

Ziaee, A., Esmailzadehha, N., Ghorbani, A., \& Asefzadeh, S. (2013) Association between Uric Acid and Metabolic Syndrome in Qazvin Metabolic Diseases Study (QMDS), Iran. Glob J Health Sci, 5(1), $155-65$. http://dx.doi.org/10.5539/gjhs.v5n1p155 